\title{
Influência da Regulagem de Parâmetros de Soldagem sobre a Estabilidade do Processo MIG/MAG Operando em Curto-Circuito
}

\section{(Influence of the Welding Parameter Setting on the MIG/MAG Process Stability working with Short-circuiting)}

\author{
Daniel Souza ${ }^{1}$, Marcelo Lemos Rossi ${ }^{1}$, Flávio Keocheguerians ${ }^{2}$, Vinícius Castanheira do Nascimento ${ }^{2}$, Louriel Oliveira Vilarinho ${ }^{1}$ \\ Américo Scotti ${ }^{1}$ \\ ${ }^{1}$ Universidade Federal de Uberlândia, Faculdade de Engenharia Mecânica,Uberlândia, Minas Gerais, Brasil,dsouza@mecanica.ufu. \\ br; marcelo.rossi@mec.ufu.br; vilarinho@mecanica.ufu.br; ascotti@mecanica.ufu.br \\ ${ }^{2}$ Air Products Brasil Ltda, São Paulo, São Paulo, Brasil \\ KEOCHEF2@airproducts.com; vcnascimento@hotmail.com
}

\begin{abstract}
Resumo
Devido ao potencial de aplicabilidade do processo MIG/MAG no modo de transferência por curto-circuito, torna-se importante o pleno entendimento da regulagem dos parâmetros sobre a estabilidade da transferência metálica e suas conseqüências sobre a geração de respingos. Soldagens de simples deposição sobre chapas foram realizadas para verificar a influência da variação da tensão, DBCP e das taxas de crescimento e decrescimento da corrente na estabilidade da transferência por curto-circuito, utilizando-se como gás de proteção 3 misturas largamente utilizadas na prática. Como critério de comparação, foi quantificada a regularidade da transferência através de um índice a partir do comportamento do sinal de tensão de soldagem. Os resultados mostram que, operando em curtocircuito, a tensão regulada tem forte influência sobre a estabilidade de transferência, existindo uma faixa ótima. Esta faixa é fortemente influenciada pelo tipo de gás, valor da corrente, DBCP e regulagem do fator de indução. Quanto menor o teor de CO ${ }_{2}$ mais regular se torna a transferência. O efeito do fator indutivo depende do teor de $\mathrm{CO}_{2}$ na mistura.
\end{abstract}

Palavras-chave: MIG/MAG; curto-circuito; estabilidade da transferência metálica; faixa de trabalho

Abstract: Due to the wide applicability of short-circuiting GMA welding, a fully understanding of the parameter settings on the metal transfer stability turn into an important issue. Bead-on-plate welds were carried out for assessing the influence of voltage, CTWD and up and down current rates over the metal transfer regularity, using 3 commercial shielding gas blends. As comparative criterion, the transfer regularity was quantified through an index taken from voltage and current traces. The results shown that, working with shortcircuits, the setting voltage has strong influence on the metal transfer stability; there is an optimum range. This range is remarkably influenced by the shielding gas type, current value, CTWD and inductance factor settings. The lower the CO ${ }_{2}$ content in the blend, the more regular the transfer. The inductance factor effect is dependant of the $\mathrm{CO}_{2}$ content in the blend.

Key-words: $M I G / M A G$; short-circuiting; metal transfer stability; operational range.

\section{Introdução}

O processo MIG/MAG é um dos processos de soldagem mais utilizados na indústria atualmente. Devido a sua importância na fabricação, caracteriza-se a necessidade de se garantir uma boa qualidade dos cordões de solda. Um dos modos operacionais mais utilizados neste processo é o da soldagem por curto-circuito. Com ele, a transferência de metal se dá basicamente por tensão superficial, quando a gota toca o metal líquido da poça. Este modo de transferência produz uma poça de fusão relativamente pequena, de rápida solidificação, sendo indicado para soldagem de seções finas ou soldagens fora da posição plana.

(Recebido em 19/04/2010; Texto final em 02/03/2011). Artigo originalmente publicado no CONSOLDA 2009,
Por causa da importância da aplicação desse tipo de transferência na soldagem pelo processo MIG/MAG, inúmeros estudos foram realizados com objetivo de entender e aperfeiçoar este tipo de transferência. O principal problema da transferência por curto-circuito é a geração de respingos, que diminui a capacidade de produção, seja devido à perda de material de adição ou à necessidade de gasto de recursos para sua retirada. Muitos destes estudos, voltados para a redução da geração de respingos, baseiam-se na melhoria da estabilidade de curtoscircuitos através da correta regulagem dos parâmetros de soldagem. Segundo Dutra et al [1], a estabilidade deste modo de operação pode ser traduzida como a regularidade na formação e na separação das gotas metálicas, podendo ser avaliada com base na repetibilidade temporal dos valores instantâneos de tensão e corrente. Dos denominados oscilogramas, pode-se extrair indicativos da regularidade da transferência e, com isso, comparar, quantitativamente, soldagens realizadas sob diferentes combinações de parâmetros e variáveis de processo. 
Em sua revisão da literatura, Hermans e Den Ouden [2] citam que podem ser distinguidas três causas para instabilidade em transferência por curto-circuito:

- Curtos-circuitos instantâneos: o eletrodo toca a poça de soldagem por um curto período de tempo, mas não há transferência de metal;

- Falha de reignição do arco;

- Variação na velocidade de alimentação de arame.

Para poder avaliar o desempenho do processo, muitos autores propuseram índices que mensurassem a estabilidade do mesmo quando operando em curto-circuito. Norrish [3, página 252] cita vários índices de estabilidade propostos por outros autores, todos baseados na análise estatística dos sinais dos parâmetros de soldagem. Baixo e Dutra [4] utilizaram como indicativos de estabilidade o desvio padrão dos picos de corrente, do período de transferência e de tempo de curtocircuito. Segundo estes autores, o desvio padrão dos picos de corrente foi, entre os índices analisados, o que apresentou maior sensibilidade à ocorrência de irregularidades na transferência. Porém, esta grande sensibilidade pode resultar em problemas de repetibilidade do indicativo, uma vez que em situações de transferência realizada sob o mesmo procedimento de soldagem, e resultando em depósitos aparentemente de mesmas características, o desvio padrão dos picos de corrente pode apresentar variações da ordem de 50\%. Já Fonseca; Avelar; Modenesi [5] utilizaram como indicativos de estabilidade a variação do período de transferência $(\mathrm{T})$, o tempo médio de duração de um curto-circuito (tcc), o fator de curto-circuito $(\mathrm{Fcc}=\mathrm{tcc} / \mathrm{T})$ e um fator de respingos $(\mathrm{R})$, que foi definido pelos autores como a razão entre o peso dos respingos e o peso do metal de adição (metal depositado + respingos). Segundo estes, como forma de agregar o período de transferência (T) e o fator de respingos (R), definiu-se um índice de estabilidade (IE) do processo como:

$$
I E=\frac{100}{T \times R}
$$

Em outro trabalho sobre estabilidade do processo operando em curto-circuito, Silva; Marques; Modenesi [6] utilizam histogramas de períodos de transferência para diferentes valores de tensão. Neste trabalho, os autores relacionam o tipo de distribuição do histograma com a estabilidade do processo, medida pela quantidade de respingos gerada, concluindo que em condições mais favoráveis de operação a distribuição de períodos de transferência tende a ser multimodal. Suban e Tusek [7] utilizam índices de estabilidade baseados em parâmetros estatísticos, parecidos com os dos autores anteriormente citados, mas utilizaram também um índice baseado em gráficos com aspecto de laços, que são gerados a partir dos valores instantâneos dos pares de coordenada da corrente e da tensão. Nestes gráficos, quanto maior a uniformidade dos laços, mais estável está o processo. Já Roca; Fals; Fernández [8] também apresentam um índice de estabilidade de curto-circuito baseado nos laços gerados por gráficos de tensão em função da corrente. Porém, nesse estudo, os autores propuseram um algoritmo para o cálculo da área de cada laço gerado no gráfico e usaram como índice de estabilidade o desvio padrão da média destas áreas calculadas. Roca et al [9] utilizam um índice baseado no sinal de emissão acústica, utilizando o desvio padrão dos tempos entre curtos-circuitos e desvio padrão das amplitudes dos picos de sinais acústicos dos curtos. Kang and Rhee [10] capturam os respingos gerados durante a soldagem e relacionaram com os sinais elétricos adquiridos. Eles propuseram um índice baseado em regressões lineares e não lineares para estimar a quantidade de respingos, tomando como fatores de entrada o período de curto-circuito, os tempos de arco aberto, curto-circuito, pico de corrente de curto, corrente instantânea de curto-circuito, corrente média pelo período de curto-circuito e os respectivos desvios padrões destes parâmetros. Dentre os resultados, foi verificado que entre período de curto-circuito e o tempo de arco aberto (assim como entre seus desvios padrões) havia uma grande correlação e, por isso, deveria se escolher um dos dois (o período ou o tempo de arco aberto) para análise, sob pena de causar um erro na mesma.

Fica, assim, clara a preocupação em se caracterizar estabilidade da transferência da soldagem MIG/MAG com curtos-circuitos. Porém, poucos autores estudaram a influência dos parâmetros na estabilidade da transferência, pelo menos de uma forma mais sistemática. Por exemplo, Dutra [11] estuda o efeito da indutância sobre a estabilidade em função do gás de proteção utilizado, mas não leva em consideração o efeito que o comprimento de arco poderia ter. Não se encontrou também estudos sobre o efeito da distância bico de contato-peça (DBCP) sobre a estabilidade. Desta forma, neste trabalho se propõe a avaliar, de forma sistemática, a estabilidade da transferência sob a influência da variação na regulagem da DBCP, comprimento de arco e indutância, na soldagem MIG/MAG com 3 diferentes tipos de gases.

\section{Metodologia}

\subsection{Aplicação de um Critério para Quantificar Estabilidade em MIG/MAG com Curto-Circuito}

Para comparação quantitativa entre as condições de soldagem, no presente estudo aplicou-se um critério formado por dois parâmetros, a saber, Índice Vilarinho de Regularidade da Transferência em Curto-Circuito (IVcc) e Freqüência de Corte para Tamanho Máximo de Gota para Transferência por CurtoCircuito $\left(\mathrm{F}_{\text {corte }}\right)$. O índice de regularidade IVcc é baseado na premissa de que a estabilidade do processo de transferência por curto-circuito está ligada com a constância dos tempos em curtocircuito e em arco aberto, ou seja, acredita-se que, se os tempos sofram pouca variação tanto em curto-circuito como em arco aberto, o processo está estável. Nessa abordagem, as constâncias nos tempos é medida através do coeficiente de variação, que leva em conta não somente o desvio padrão da amostra, mas também sua média. Já a $\mathrm{F}_{\text {corte }}$ tenta correlacionar o tamanho da gota antes de entrar contato com a poça com as freqüências de curtos-circuitos. Gotas muito grandes não representam uma condição adequada para transferência por curto-circuito. Abaixo de uma certa freqüência há grandes possibilidades das gotas serem grosseiras, ou seja, o processo está operando num modo 
combinado conhecido como globular/curto-circuito $[12,13]$.

Para utilização do critério proposto, deve-se primeiro calcular $\mathrm{F}_{\text {corte }}$. Assume-se, arbitrariamente que gotas com diâmetro maiores do que $25 \%$ do diâmetro do arame-eletrodo já representam o modo de transferência combinado. Para o cálculo da $\mathrm{F}_{\text {corte }}$ (em função do tamanho da gota) utilizou-se a Equação 1.

$F_{\text {corte }}=\frac{3 V_{\text {alim }} d^{2}}{2 d_{q}{ }^{3}}$

onde $d$ = diâmetro do eletrodo; Valim $=$ velocidade de alimentação de arame; $d g=$ diâmetro da gota .

Em seguida aplica-se o Índice Vilarinho de Regularidade da Transferência em Curto-Circuito (IVcc), apresentado pela Equação 2. Considerando somente os valores de freqüência de curto-circuito abaixo da freqüência de corte $\left(\mathrm{F}_{\text {corte }}\right)$, quanto menor o valor do índice de regularidade, melhor a regularidade.

$I V C C=\frac{\sigma t_{c c}}{t_{c c}}+\frac{\sigma t_{a b}}{t_{a b}}$

onde $\sigma t c c=$ desvio padrão da média do tempo de curto-circuito; $\sigma t a b=$ desvio padrão da média do tempo de arco aberto, tcc $=$ média do tempo de curto-circuito; tab = média do tempo de arco aberto.

\subsection{Soldagens de Varredura para Determinação da Região de Transferência por Curto-Circuito}

Para realização dos experimentos (soldagens de simples deposição sobre chapas de aço ao carbono de $12,7 \mathrm{~mm}$ de espessura), foi utilizada uma fonte eletrônica multiprocesso do tipo inversora (Power Wave 455M/STT - Lincoln Electric - a identificação se justifica pelo comportamento diferenciado entre equipamentos eletrônicos) regulada para operar no modo de tensão constante, em CC+. Foi utilizado um arame-eletrodo de 1,2 mm, da classe AWS ER70S-6. Como gás de proteção, utilizou-se três misturas gasosas binárias a base de argônio, com teores nominais (entre parênteses, os valores analisados) de $\mathrm{CO}_{2}$ de $8(7,4), 15(14,2)$ e $25(24,3) \%$. A distância bico de contatopeça foi mantida sempre em $12 \mathrm{~mm}$ (condição média tipicamente aplicada na prática para este tipo de soldagem), com a tocha posicionada de forma perpendicular à peça. A movimentação da tocha foi feita de forma mecanizada.

Para realização da varredura nos valores de tensão e velocidade de alimentação que proporcionassem transferência por curto-circuito, escolheram-se valores de corrente condizente com este tipo de transferência. A faixa de corrente escolhida foi de 100 a $200 \mathrm{~A}$, intercalada com os valores de 145 e 175 A. Para a determinação das velocidades de alimentação que proporcionassem as correntes desejadas, iniciou-se a soldagem com uma condição de valor de tensão que proporcionasse transferência por curto-circuito. Soldando nesta condição de forma contínua em uma chapa, variou-se a velocidade de alimentação até que a corrente almejada (ou valor próximo dela) fosse conseguida. A relação velocidade de soldagem/ velocidade de alimentação foi mantida constante com intuito de manter a quantidade de material depositado também constante nas demais soldagens (evitando o efeito do volume da poça nas comparações).

Para se determinar a tensão mínima de soldagem para cada valor de velocidade de alimentação definido, iniciou-se a soldagem regulando-se uma das velocidades de alimentação e um valor de tensão que proporcione transferência por curtocircuito. Depois, soldando continuamente, decrementou-se o valor de tensão em $1 \mathrm{~V}$ a cada $20 \mathrm{~s}$, até que, visualmente, a transferência tornasse instável (provocando grande quantidade de respingos). Para se determinar o valor de tensão máxima, incrementou-se a tensão escalonadamente até que se percebesse visualmente que o modo transferência atingisse uma condição combinada de curto-circuito/globular, caracterizada pelo grande espaço de tempo entre um curto e outro.

\section{Resultados e Discussão}

A Tabela 1 mostra os valores de regulagem das velocidades de alimentação (como indicado no painel do equipamento, com duas casas decimais) para se alcançar as correntes desejadas. Também apresenta a Freqüência de Corte para Tamanho Máximo de Gota para Transferência por Curto-Circuito $\left(\mathrm{F}_{\text {corte }}\right)$ calculada em função da velocidade de alimentação para todos os gases ensaiados. Observa-se que as velocidades de alimentação que proporcionaram uma dada corrente não foram significativamente influenciadas pelo gás de proteção, na dada DBCP e em curtocircuito.

\subsection{Influência da Tensão na Regularidade do Processo}

A Figura 1 apresenta o efeito da variação da tensão de soldagem (valor médio monitorado) sobre a freqüência medida de curto-circuito $(\mathrm{Fcc})$ e índice de regularidade (IVcc) para velocidade de alimentação de $2,05 \mathrm{~m} / \mathrm{min}(107 \mathrm{~A})$ e gás de proteção $\mathrm{Ar}+8 \% \mathrm{CO}_{2}$. De forma similar, os mesmos gráficos foram levantados para as demais combinações da Tabela 1, mas por falta de espaço não são aqui apresentados. Observandose as curvas de todos os experimentos, a freqüência tem uma tendência de crescer até um máximo e de cair continuamente para maiores valores de tensão de soldagem. Menores valores de freqüência são esperados para maiores valores de tensão (proporcionalmente maiores comprimentos de arco), pois se criam condições para a gota crescer antes de se destacar. Já os valores muito baixos de tensão, para arcos muito curtos, pode ser justificado pelo caráter explosivo da transferência nestas condições, o que faz o arco atingir valores altos logo em seguida de cada aproximação gota-poça, demorando um pouco mais a provocar uma nova aproximação. Observando-se agora as curvas do índice de estabilidade em função da tensão de soldagem (exemplificada na Figura 1(b), pode-se verificar que o índice tem a característica de diminuir e depois novamente aumentar seu valor com o aumento da tensão de soldagem. Como valores menores do índice indicam melhor estabilidade, verifica-se que o processo tem pouca estabilidade para tensões muito baixas e muito altas, como esperado. Kang and Rhee [10] também obtiveram resultados parecidos quando capturaram a quantidade 
Tabela 1. Velocidade de alimentação regulada no equipamento para se obter a corrente desejada e os respectivos valores calculados para freqüência mínima de corte $\left(\mathrm{F}_{\text {corte }}\right)$, mantendo-se $\mathrm{DBCP}$ de $12 \mathrm{~mm}$ e uma tensão regulada para curto-circuito estável para cada combinação

\begin{tabular}{|c|c|c|c|c|}
\hline Gás de proteção & $\begin{array}{c}\text { Tensão de soldagem } \\
\text { (V) } \\
\text { (regulada) }\end{array}$ & $\begin{array}{l}\text { Velocidade de Alimentação } \\
\text { (m/min) } \\
\text { (regulada) }\end{array}$ & $\begin{array}{l}\text { Corrente de Soldagem (A) } \\
\quad \text { (monitorada) }\end{array}$ & $\begin{array}{c}\mathrm{F}_{\text {corte }} \\
(\mathrm{Hz}) \\
\text { (calculada) }\end{array}$ \\
\hline \multirow{4}{*}{$\mathrm{Ar}+8 \% \mathrm{CO}_{2}$} & 16,0 & 2,05 & 107 & 21,9 \\
\hline & 16,0 & 2,76 & 142 & 29,4 \\
\hline & 17,0 & 3,65 & 172 & 38,9 \\
\hline & 17,0 & 4,69 & 208 & 50,0 \\
\hline \multirow{4}{*}{$\mathrm{Ar}+15 \% \mathrm{CO}_{2}$} & 17,0 & 2,00 & 104 & 21,3 \\
\hline & 17,0 & 2,81 & 148 & 30,0 \\
\hline & 17,0 & 3,60 & 175 & 38,4 \\
\hline & 17,0 & 4,80 & 207 & 51,2 \\
\hline \multirow{4}{*}{$\mathrm{Ar}+25 \% \mathrm{CO}_{2}$} & 19,0 & 2,00 & 109 & 21,3 \\
\hline & 19,0 & 2,71 & 148 & 28,9 \\
\hline & 19,0 & 3,60 & 181 & 38,4 \\
\hline & 19,0 & 4,70 & 213 & 50,1 \\
\hline
\end{tabular}

de respingos gerada em função da tensão de soldagem para quatro valores de corrente de soldagem. Os gráficos destes autores são mostrados na Figura 2. Novamente pela Figura 1(b), é possível notar que o mínimo de IVcc não coincide com o máximo de Fcc. Para o refino da faixa de tensão obtida nos experimentos, um Critério para Estabilidade de Transferência em MIG/MAG com Curto-Circuito foi aplicado. Utilizando-se das curvas de freqüência (exemplificada na Figura 1(a) e os valores da freqüência de corte ( $F_{\text {corte }}$ na Tabela 1$)$ determinaram-se inicialmente os valores de tensão que proporcionavam somente transferência por curto-circuito, como mostra a Figura 1(b). Trabalhando agora apenas sobre a faixa restante dos valores de tensão de soldagem, determinou-se arbitrariamente os valores de tensão que estão no vale das curvas do índice IVcc; no caso da Figura 1(b), tomou-se como regular as tensões entre 14,5 e $17,5 \mathrm{~V}$.

A Figura 3 apresenta os pontos considerados em curtocircuito estável após a aplicação do Critério para Estabilidade de Transferência em MIG/MAG com Curto-Circuito. Observase que para misturas mais ricas em $\mathrm{CO}_{2}$ existe uma tendência da faixa de operação regular ter valores mais altos de tensão, ou seja, na prática, deve-se trabalhar com maiores valores de tensão quando se utiliza gases mais ricos em $\mathrm{CO}_{2}$.

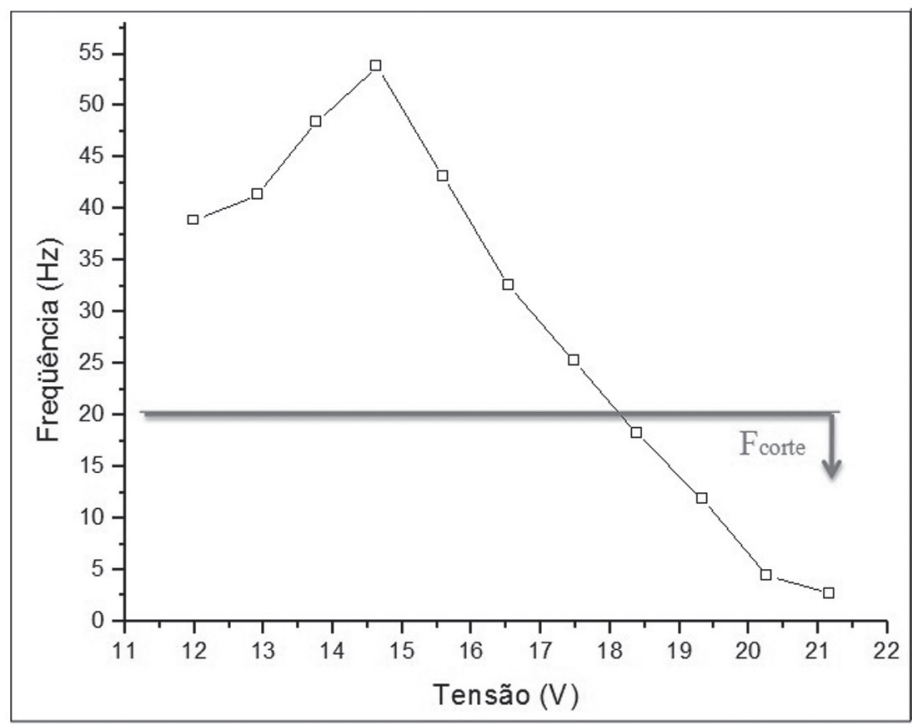

(a)

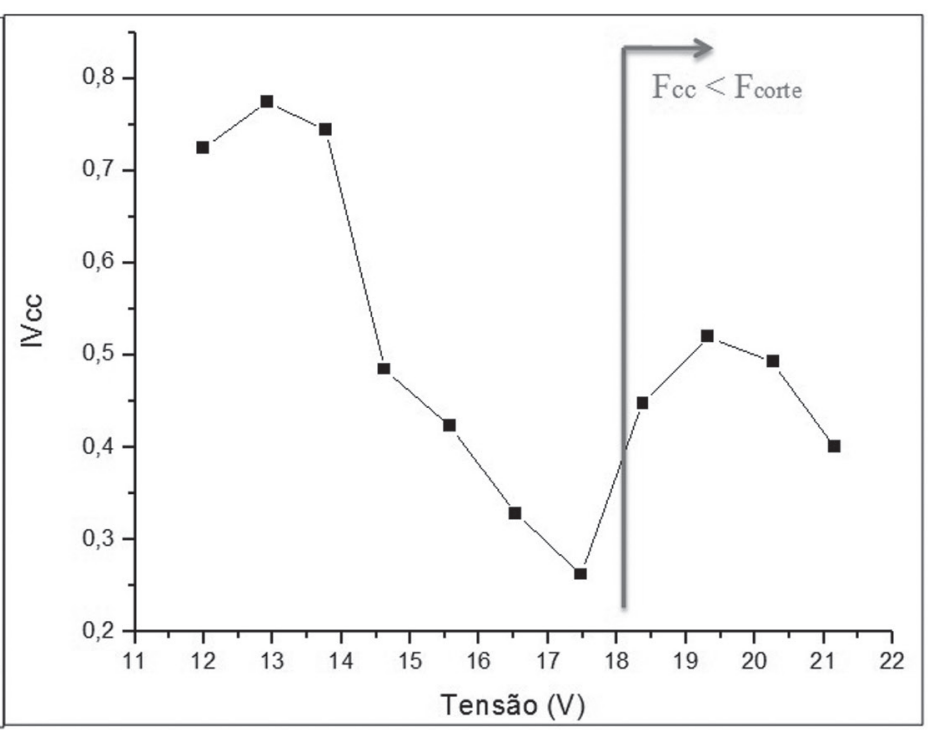

(b)

Figura 1. Curvas de freqüência de curto-circuito medida (a) e índice de regularidade (IVcc) calculado (b), em função da tensão de soldagem para velocidade de alimentação de $2,05 \mathrm{~m} / \mathrm{min}(107 \mathrm{~A})$ e gás de proteção $\mathrm{Ar}+8 \% \mathrm{CO}_{2}$ 


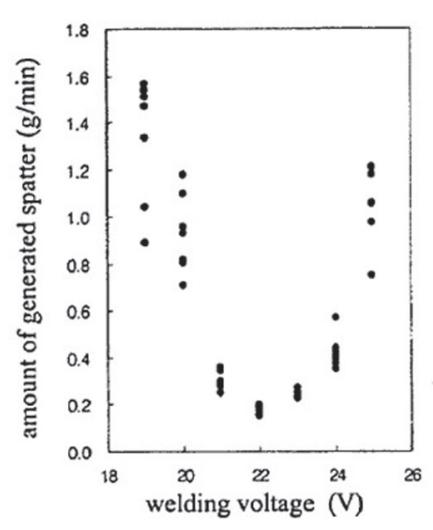

(a) $150 \mathrm{~A}$

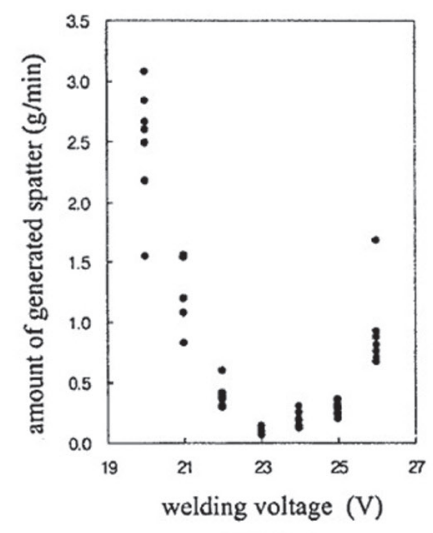

(b) $200 \mathrm{~A}$

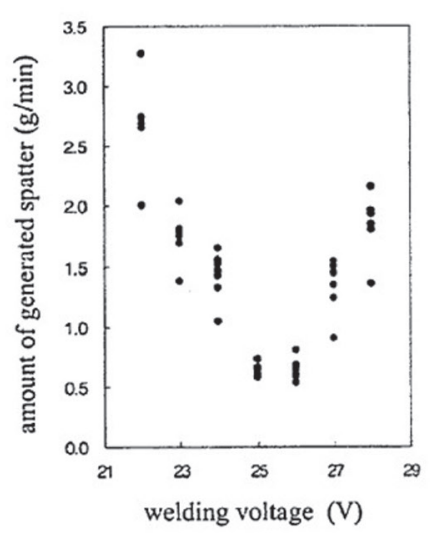

(c) $225 \mathrm{~A}$

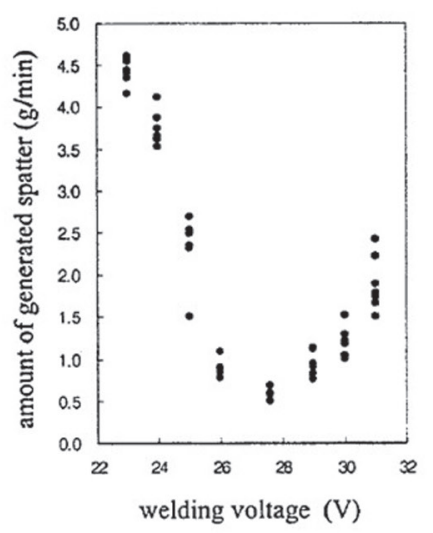

(d) $250 \mathrm{~A}$

Figura 2. Curvas da quantidade de respingos gerados em função da tensão de soldagem para 4 valores de corrente [10]

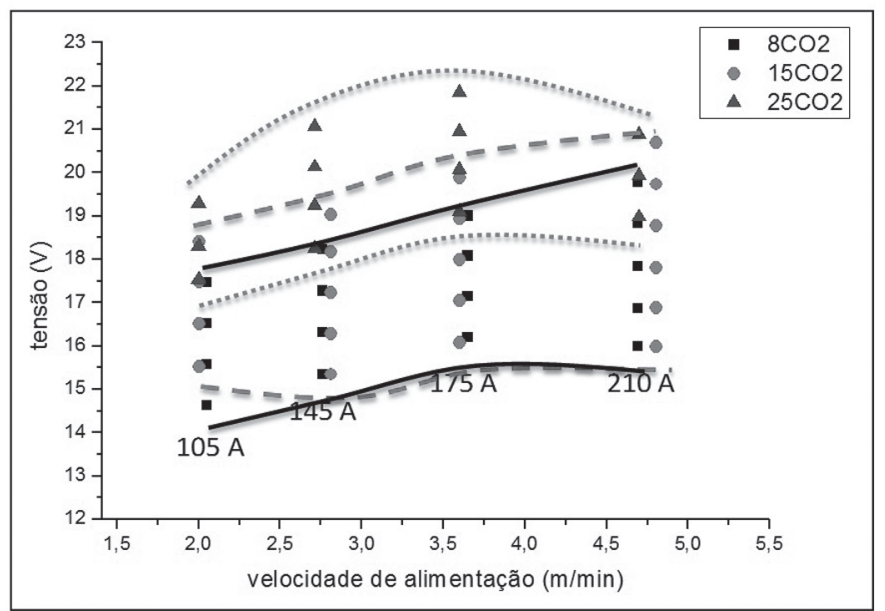

Figura 3. Regiões de curtos-circuitos estáveis em função do gás de proteção utilizado

\subsection{Influência do Aumento da DBCP na Regularidade do Processo}

Foram realizadas soldagens alterando-se a DBCP de $12 \mathrm{~mm}$ para $16 \mathrm{~mm}$, com atmosfera gasosa de $\mathrm{Ar}+8 \% \mathrm{CO}_{2}$ e corrente de 150 A. Para tal, encontrou-se a velocidade de alimentação que proporcionava a corrente desejada para uma determinada tensão. Com essa velocidade de alimentação, encontrou-se a faixa de tensão (tensão mínima e máxima) que, visualmente, promovia transferência por curto-circuito (conforme item 2.2). Então, utilizando o Critério de Estabilidade, selecionou-se a faixa de tensão que proporcionava uma transferência estável.

A Figura 4 demonstra os resultados obtidos e verifica-se que o aumento da DBCP alarga a faixa de tensão de curto-circuito estável, mas essa faixa possui valores de tensão mais baixos. A princípio, pensando na maior queda de tensão de soldagem que um maior comprimento livre do eletrodo levaria, pode-se tentar explicar esse fenômeno através da equação geral de consumo (Equação 3) e pelo deslocamento da característica estática do arco sobre a da fonte. Com algumas hipóteses é possível verificar que o aumento da DBCP sem variar a velocidade de alimentação (consumo) leva à diminuição da corrente, ao aumento do comprimento do arco e ao aumento do comprimento energizado do eletrodo (a metodologia utilizada para chegar a estes resultados pode ser encontrada na publicação de Scotti e Ponomarev [13], páginas 112-118). Ferreira Filho e Ferraresi [14] encontraram resultados que corroboram a hipótese acima, mostrando que o aumento da DBCP diminui o valor da corrente de soldagem (Figura 5), quando todos os parâmetros são mantidos fixos e utilizando uma fonte eletrônica regulada para operar em tensão constante. Diante disto, toma-se como verdadeira a hipótese de aumento do comprimento do arco como conseqüência do aumento da DBCP.

$C=\alpha I+\beta l I^{2}$

onde $C=$ consumo; $I=$ corrente $l=$ comprimento energizado de eletrodo; $\alpha$ e $\beta$ são coeficientes que dependem da polaridade, composição e dimensões do eletrodo, gás de proteção etc.

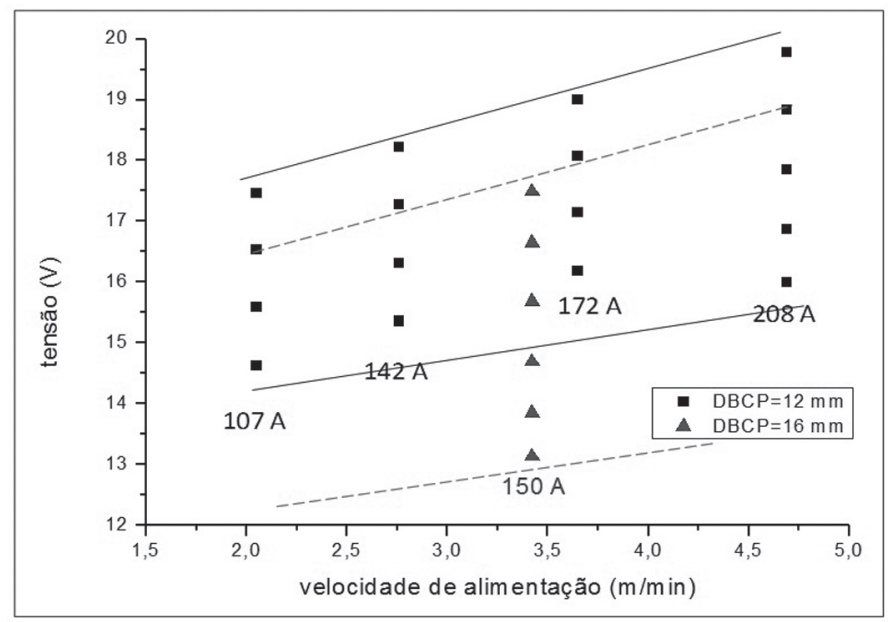

Figura 4. Influência do aumento da DBCP na faixa de tensão de soldagem com o processo operando com proteção de $\mathrm{Ar}+$ $8 \% \mathrm{CO}_{2}$ na região de estabilidade 


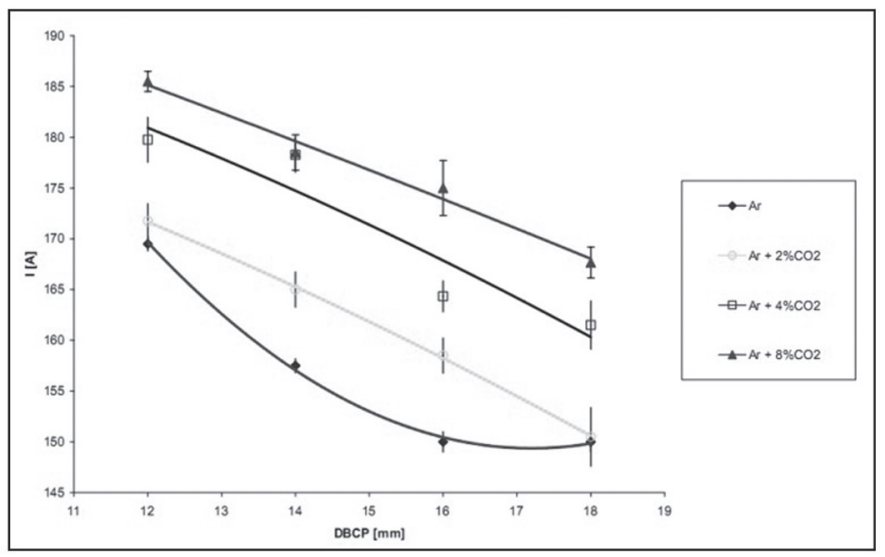

Figura 5. Influencia da DBCP na corrente para $\mathrm{Ar}$ e $\mathrm{Ar}+\mathrm{CO}_{2}$, utilizando arame-eletrodo ER430 de 1,2 mm de diâmetro, tensão de referência de $20 \mathrm{~V}$, velocidade de soldagem de 20 $\mathrm{cm} / \mathrm{min}$ e velocidade de alimentação de $5,3 \mathrm{~m} / \mathrm{min}$ [14]

Por outro lado, foi demonstrado no item anterior que existe uma relação entre o comprimento do arco (avaliado pela tensão) e a estabilidade do processo. Portanto, acredita-se que o aumento do comprimento do arco devido ao aumento da DBCP provoque a desestabilização do processo. Assim, para se corrigir o tamanho do arco deve-se diminuir a tensão de soldagem. Por isso, para maiores valores de DBCP é necessário a utilização de tensões mais baixas para manter o processo operando estável. Entretanto, este resultado discorda de Roca et al. [8], que verificaram que a mudança na $\mathrm{DBCP}$ de 6 para $10 \mathrm{~mm}$ não teria alterado significativamente a regularidade do processo.

\subsection{Influência do Fator Indutivo na Regularidade do Processo}

\subsubsection{Caracterização da Indutância do Equipamento de Soldagem}

A melhor forma de se fazer referência à indutância de um equipamento é pelo termo "efeito indutivo", ou seja, as taxas de crescimento e decrescimento da corrente, pois a indutância do sistema não depende só da fonte, mas também do arco, etc. Para a caracterização do efeito indutivo, variou-se a posição de regulagem no equipamento em toda sua faixa (de -10 a 10), variando-se o valor da posição em degraus de 2,5. Os parâmetros utilizados para todos os testes foram tensão de referência regulada no equipamento de $22 \mathrm{~V}$, velocidade de alimentação de $2,71 \mathrm{~m} / \mathrm{min}$, DBCP de $12 \mathrm{~mm}$ e vazão de gás de 14 1/min. Foram utilizadas as misturas de $\mathrm{Ar}+8 \% \mathrm{CO}_{2}$ e $\mathrm{Ar}+25 \% \mathrm{CO}_{2}$.

A Figura 6 mostra o comportamento das taxas de subida e de descida das correntes para ambas as misturas de gases ao se alterar a posição de regulagem do efeito indutivo, caracterizando o aumento das taxas de subida e descida da corrente quando a regulagem do efeito indutivo passa de -10 para +10 . Ou seja, na posição -10 é como se a indutância fosse maior (menor crescimento da corrente), reduzindo-se na direção de +10 . Porém, o gás de proteção (pelo menos entre estes dois) não parece ter grandes influências sobre di/dt.

AFigura 7 mostra os valores médios das medidas de freqüência de curto-circuito, tensão e corrente em função da posição de regulagem do efeito indutivo, com todos os curtos-circuitos ou retirando-se os curtos incipientes (muito rápidos, que não transferem metal por tensão superficial, neste trabalho adotados como aqueles cuja duração fosse $\leq 2 \mathrm{~ms}$ ). Pode-se verificar que a variação do valor regulado para o efeito indutivo não modifica a freqüência de ocorrência dos curtos-circuitos, nem a tensão ou a corrente média (fato constatado para as condições do presente trabalho, mas discordante de experimentos feitos com outros equipamentos, como reportado por Dutra [11]. Entretanto, a freqüência de curto-circuito é fortemente dependente do gás de proteção, passando de aproximadamente 20 para $60 \mathrm{~Hz}$ quando se mudou o teor de $\mathrm{CO}_{2}$ de $8 \%$ para $25 \%$, ao contrário da tensão e da corrente de soldagem que apresentaram mudanças muito

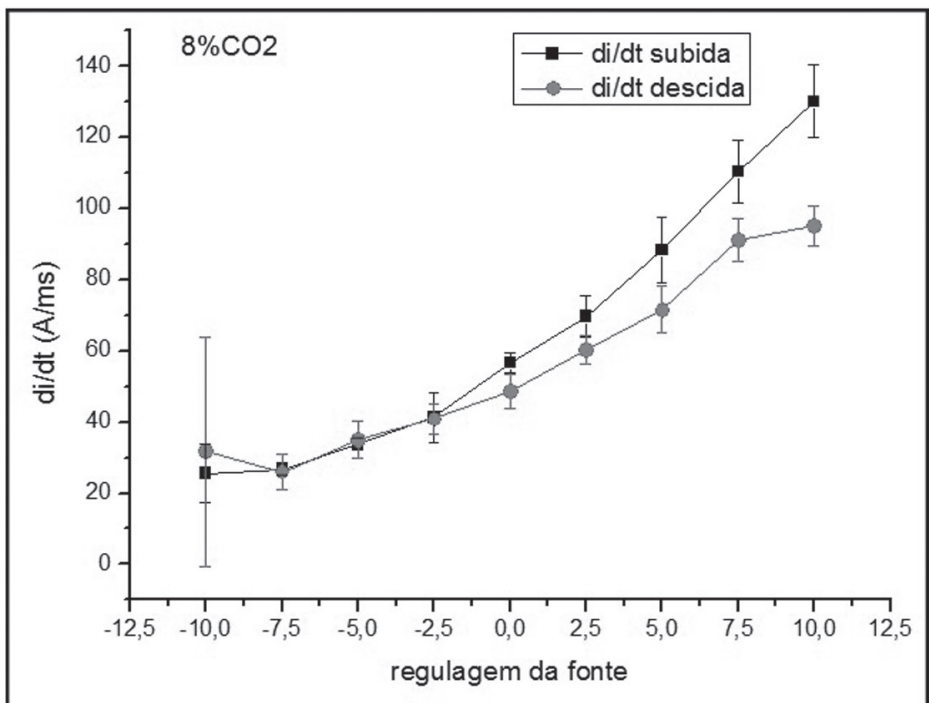

(a)

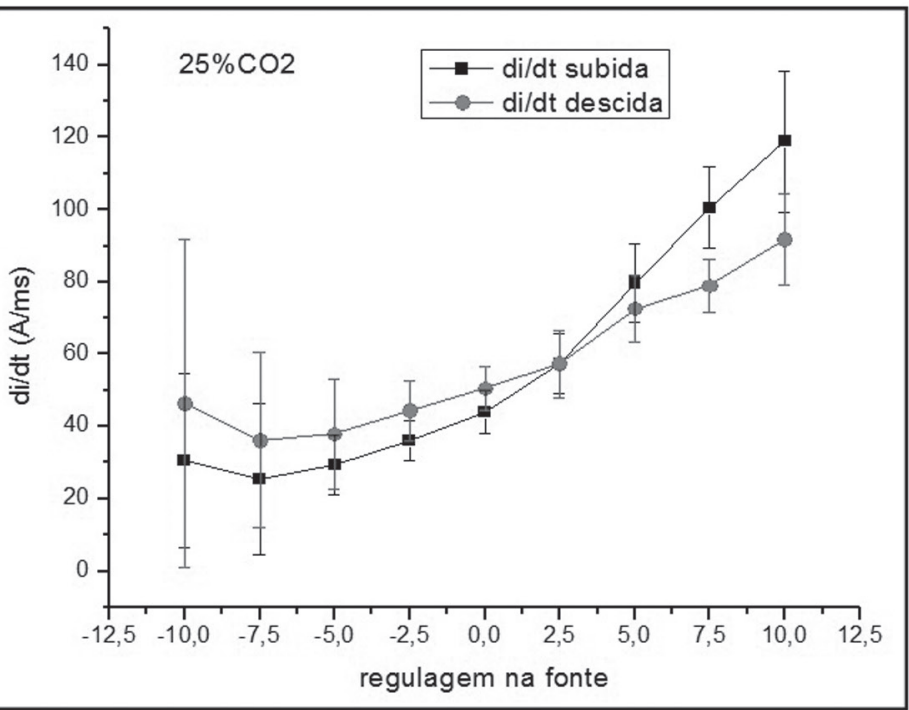

(b)

Figura 6. Valores médios das taxas de subida e de descida da corrente (di/dt) em função da regulagem do efeito indutivo da fonte para os parâmetros descritos acima. (a) Proteção gasosa: $\mathrm{Ar}+8 \% \mathrm{CO}_{2}$ (b) e $\mathrm{Ar}+25 \% \mathrm{CO}_{2}$ 

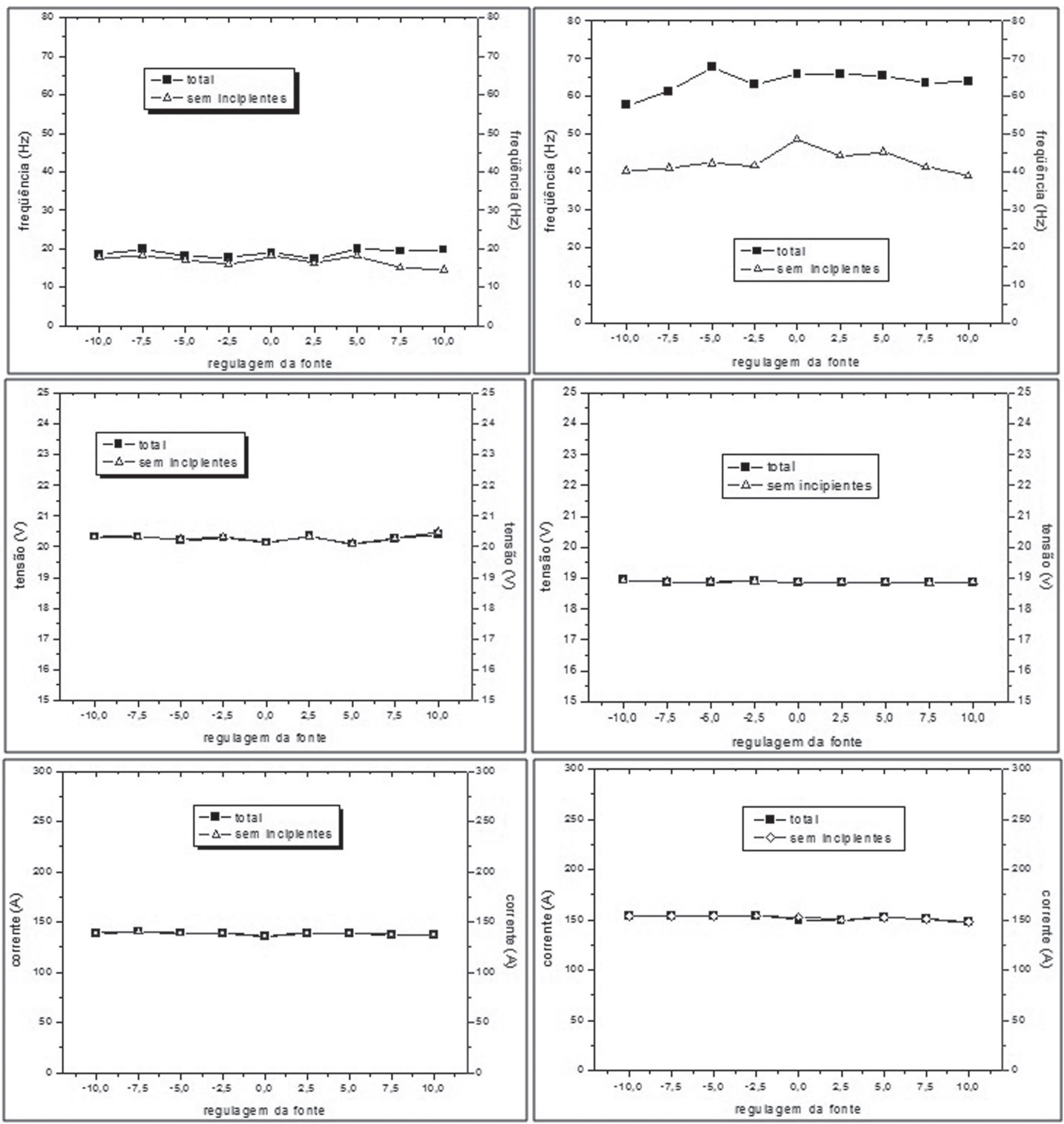

(a)

(b)

Figura 7. Demonstração da estabilidade dos parâmetros freqüência de curto-circuito, tensão e corrente ao variar o efeito indutivo. Proteção gasosa: (A) $\mathrm{Ar}+8 \% \mathrm{CO}_{2}$ e (B) $\mathrm{Ar}+25 \% \mathrm{CO}_{2}$, com tensão de referência regulada no equipamento de $22 \mathrm{~V}$ 
pequenas. Ainda pode-se observar que os curtos incipientes ocorreram em maior número para a mistura com $25 \%$ de $\mathrm{CO}_{2}$ Estes resultados concordam com os de Ponomarev et al [15] (Tabela 2). O que se pode deduzir é que numa faixa de estabilidade operacional, a variação do efeito indutivo não tem efeito sobre o período de curtos-circuitos, mas uma taxa de crescimento e decrescimento de corrente mais alta (regulagem +10 ) leva a uma corrente de curto-circuito mais alta (p. ex., no caso do $\mathrm{Ar}+8 \% \mathrm{CO}_{2}, 387$ A contra 277 para regulagem -10) e a um menor tempo de duração dos curtos (por exemplo, no caso do $\mathrm{Ar}+8 \% \mathrm{CO}_{2}, 3,40 \mathrm{~ms}$ contra 4,48 $\mathrm{ms}$ para a regulagem -10). Isto é justificável do ponto de vista energético, pois a taxa de fusão teria de ser a mesma (mesma velocidade de alimentação), assim como o tamanho das gotas em transferência estável deve ser muito similar, ou seja, a corrente, a tensão e a freqüência de transferência não se alteram em valores médios. Mas é importante destacar que não necessariamente a estabilidade de transferência teria de ser a mesma para diferentes regulagens do efeito indutivo, como será estudado no item seguinte.

Tabela 2. Valores médios de corrente, tensão e freqüência de curto-circuito, utilizando arame-eletrodo de 1,0 $\mathrm{mm}$ de diâmetro (ER70S-6), gás de proteção $\mathrm{Ar}+5 \% \mathrm{CO}_{2}+5 \%$ $\mathrm{O}_{2}, \mathrm{DBCP}=20 \mathrm{~mm}$, velocidade de alimentação $=7 \mathrm{~m} / \mathrm{min}$ e velocidade de soldagem $=0,9 \mathrm{~m} / \mathrm{min}-$ Adaptado [15]

\begin{tabular}{|c|c|c|c|c|}
\hline $\mathrm{di} / \mathrm{dt}(\mathrm{A} / \mathrm{ms})$ & $\mathrm{Um}(\mathrm{V})$ & $\operatorname{Im}(\mathrm{A})$ & $\mathrm{Fcc} *(\mathrm{~Hz})$ & $\mathrm{Fcc}(\mathrm{Hz})$ \\
\hline 160 & 21,26 & 140 & 27,6 & 40,1 \\
\hline 40 & 21,22 & 152 & 30,0 & 50,1 \\
\hline 25 & 21,25 & 144 & 27,8 & 42,2 \\
\hline
\end{tabular}

$U m=$ tensão média; $I m=$ corrente média; $F c c=$ Freqüência de curto-circuito; Fcc $*$ Freqüência de curto-circuito excluindo-se os curtos incipientes

\subsubsection{Correlação entre as Taxas de Crescimento e Decrescimento da Corrente e a Regularidade do Processo}

Para verificação da influência das taxas de crescimento e decrescimento da corrente na estabilidade do processo, apresentam-se as Figuras 8 e 9, as quais mostram em (a) o índice de regularidade em função da taxa de crescimento e em (b) em função da taxa de decrescimento da corrente, utilizando como gás de proteção $\mathrm{Ar}+8 \% \mathrm{CO}_{2}$ e $\mathrm{Ar}+25 \% \mathrm{CO}_{2}$, respectivamente. $\mathrm{Na}$ Figura 8, observa-se que a regularidade apresenta valores em torno de 0,6 para taxas de subida menores do que $80 \mathrm{~A} /$ ms e taxas de descida menores do que $65 \mathrm{~A} / \mathrm{ms}$ e de 0,85 para taxas acima destas, evidenciando que a mudança na taxa de variação da corrente influência na regularidade do processo. Observando as duas figuras, torna-se interessante destacar que o comportamento acima descrito é dependente do tipo de gás. Pela Figura 9, observa-se que, no geral, utilizando-se a mistura $\mathrm{Ar}+25 \% \mathrm{CO}_{2}$ a regularidade apresenta valores em torno de 1,2 para taxas de subida menores do que $80 \mathrm{~A} / \mathrm{ms}$ e taxas de descida menores do que $65 \mathrm{~A} / \mathrm{ms}$ e de 0,90 para taxas acima destas. Ou seja, um comportamento contrário ao observado quando utilizando $\mathrm{Ar}+8 \% \mathrm{CO}_{2}$.

Este comportamento mostra que utilizando diferentes misturas de gases de proteção, para uma mesma tensão e velocidade de alimentação, obtém-se uma correlação diferente entre as taxas de variação da corrente e a regularidade do processo. Tal resultado implica que a correlação entre a taxa de variação da corrente e a regularidade é, no mínimo, dependente do gás de proteção utilizado. Pode-se especular, até o momento, que gases mais ricos em $\mathrm{CO}_{2}$ tornam suas soldas mais estáveis com taxas de subida e descida mais rápidas, enquanto gases com menor teor alcançam maior estabilidade com baixas taxas de crescimento e decrescimento da corrente. Dutra [11], em um estudo utilizando uma fonte eletrônica que permitia a regulagem da taxa de crescimento e decrescimento separadamente, encontrou em seus resultados que a taxa de crescimento da corrente pouco influi na estabilidade. Assim, este autor, trabalhando apenas na variação da taxa de decrescimento da corrente, encontrou que a melhor estabilidade para o gás de proteção $\mathrm{Ar}+25 \% \mathrm{CO}_{2}$ seria com taxa de decrescimento de $20 \mathrm{~A} / \mathrm{ms}$ e para $100 \%$ CO2 com taxa de 44 $\mathrm{A} / \mathrm{ms}$. Esta conclusão está em concordância com os resultados presentes, confirmando a tendência de que utilizado gases com maior teor de $\mathrm{CO}_{2}$ o processo opera mais estável com taxas de crescimento e decrescimento maiores.

\subsubsection{Influência da Tensão de Soldagem sobre a Regularidade do Processo para Diferentes Taxas de Crescimento e Decrescimento da Corrente}

Soldagens foram realizadas variando-se a regulagem da tensão com a posição do efeito indutivo em -10 e +10 . A Figura 10 mostra as curvas do índice de regularidade em função da tensão de soldagem para as duas posições de regulagem, para duas misturas de gás de proteção $\left(\mathrm{Ar}+8 \% \mathrm{CO}_{2}\right.$ e $\mathrm{Ar}+25 \%$ $\mathrm{CO}_{2}$ ). Da mesma forma que como mostrado na Figura 1(b), existe um ponto de IVcc mínimo. Pelos dados da Figura 10(a) e sobrepondo os dados da Figura 1(b), pode-se dizer que o efeito indutivo apresenta pouca influência sobre a estabilidade da transferência. Este resultado poderia ser esperado já que a regulagem do efeito indutivo não fez variar a corrente, tensão ou mesmo a freqüência de transferência para uma dada tensão, como mostrado no item 3.3.1. Entretanto, pode-se observar que o gás de proteção influencia a regularidade do processo (a transferência fica menos estável para maior teor de $\mathrm{CO}_{2}$ ).

\subsubsection{Influência da Variação das Taxas de Crescimento e Decrescimento da Corrente na Faixa de Tensão em que o Processo Opera Estável}

Escolheram-se duas posições de regulagem do efeito indutivo da fonte $(-10$ e +10$)$, que sabidamente provocavam taxas de crescimento e decrescimento da corrente diferentes, e realizaram-se soldagens empregando o mesmo procedimento usado para encontrar a faixa de operação em curto-circuito estável (ver item 2.2), porém, neste caso, apenas para uma velocidade de alimentação. Os resultados dos testes são mostrados na Figura 11 para as misturas de $\mathrm{Ar}+8 \% \mathrm{CO}_{2}$ e $\mathrm{Ar}+25 \% \mathrm{CO}_{2}$. Observando-se a Figura 11(a), nota-se que a variação da taxa de crescimento e decrescimento da corrente não influencia sensivelmente a faixa de tensão em que o processo 


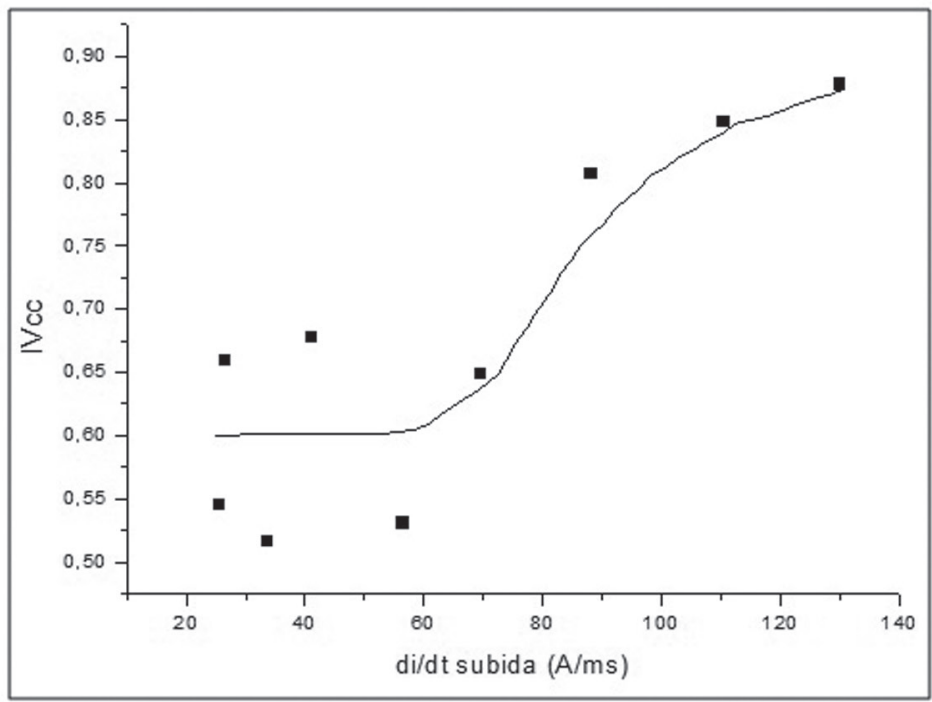

(a)

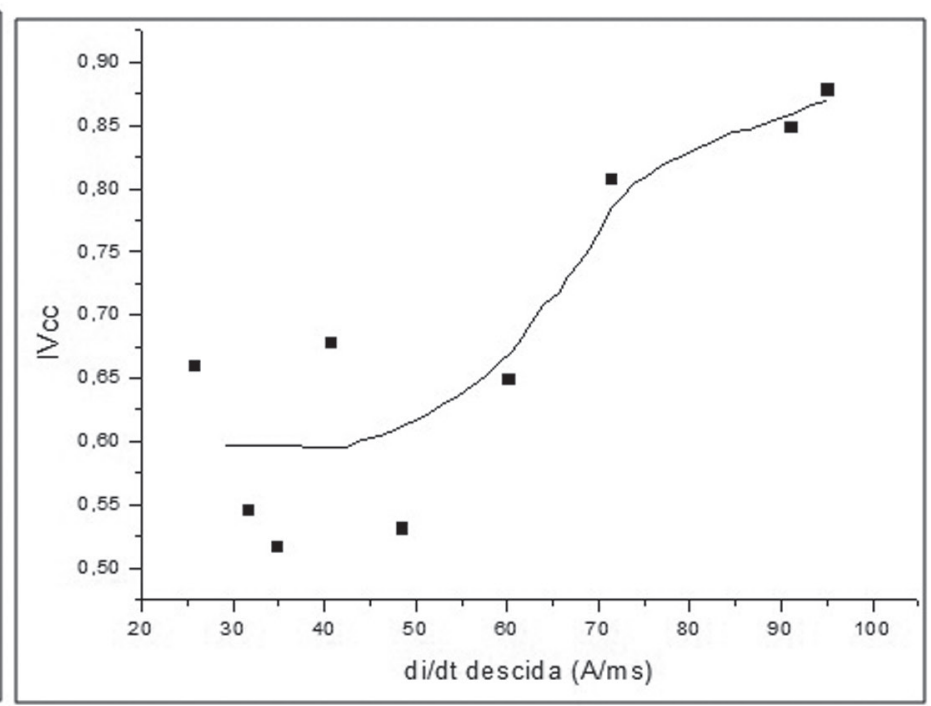

(b)

Figura 8 - Valores do índice de regularidade em função da taxa de crescimento (a) e da taxa de decrescimento (b) da corrente, utilizando como gás de proteção a mistura $\mathrm{Ar}+8 \% \mathrm{CO}_{2}(\mathrm{Ur}=22 \mathrm{~V}$ e Valim $=2,71 \mathrm{~m} / \mathrm{min})$

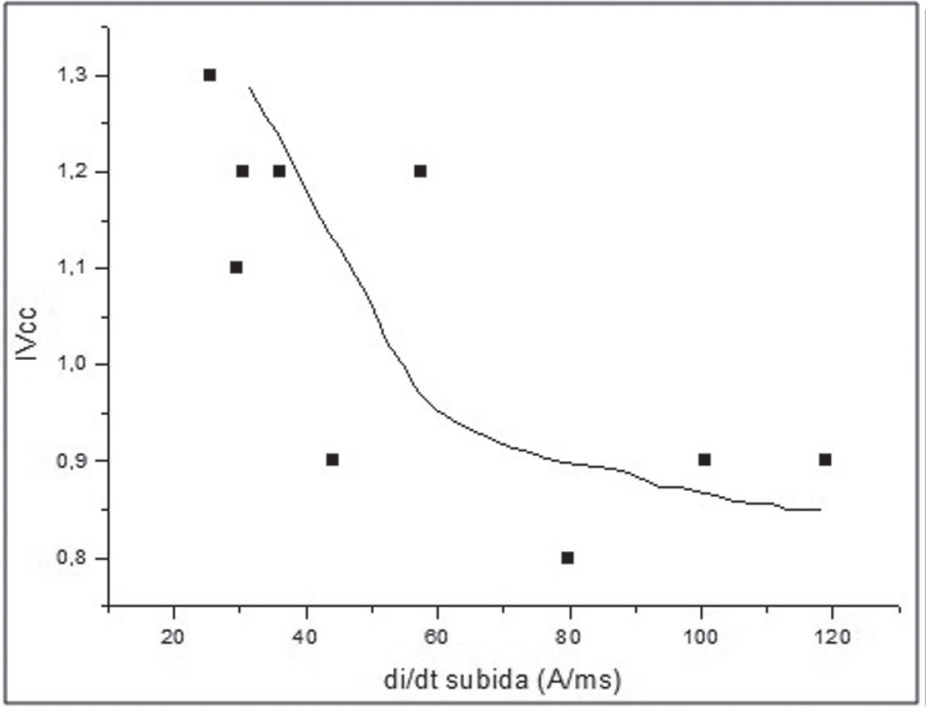

(a)

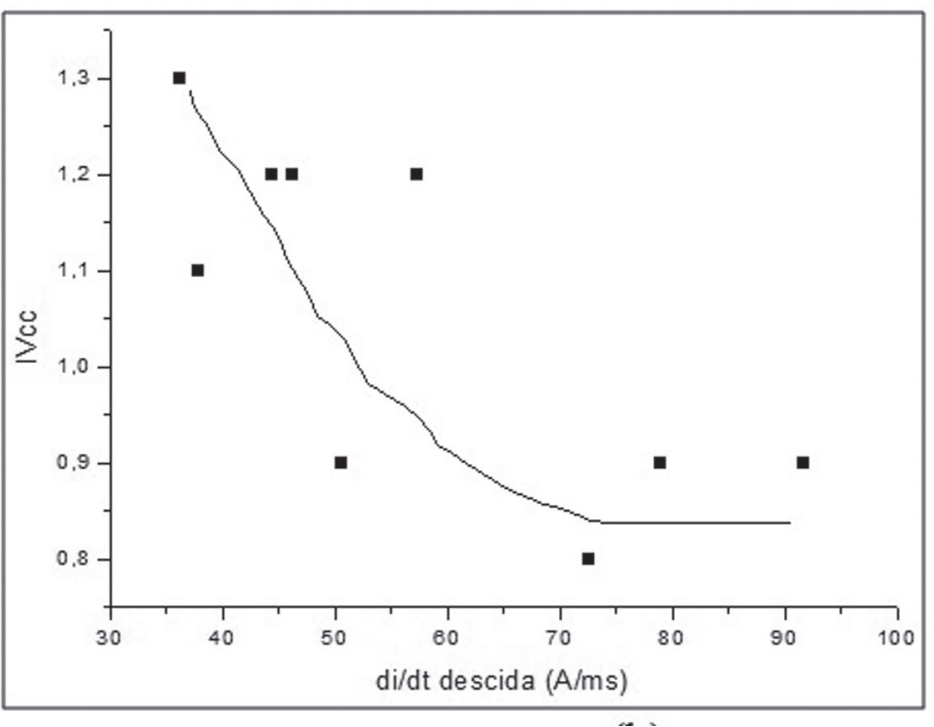

(b)

Figura 9 - Valores do índice de regularidade em função da taxa de crescimento (a) e da taxa de decrescimento (b) da corrente utilizando como gás de proteção a mistura $\mathrm{Ar}+25 \% \mathrm{CO}_{2}(\mathrm{Ur}=22 \mathrm{~V}$ e Valim $=2,76 \mathrm{~m} / \mathrm{min})$

opera em curto-circuito estável ao se usar $\mathrm{Ar}+8 \% \mathrm{CO}_{2}$ como gás de proteção, o que não ocorre quando se usa $\mathrm{Ar}+25 \% \mathrm{CO}_{2}$, Figura 11(b), na qual a regulagem da posição do efeito indutivo em -10 (menor taxa de crescimento e decrescimento da corrente) promovem uma diminuição dos valores de tensão em que o processo opera estável.

Os resultados indicam que apesar do processo operar com valores de tensão que proporcionam a melhor regularidade de operação, a mudança da taxa de crescimento e decrescimento da corrente ainda altera a regularidade do processo. No geral, a regulagem da tensão em que o processo opera com melhor estabilidade não é alterada com a mudança da taxa de variação da corrente, mas a mudança desta pode melhorar ainda mais a regularidade do processo. 


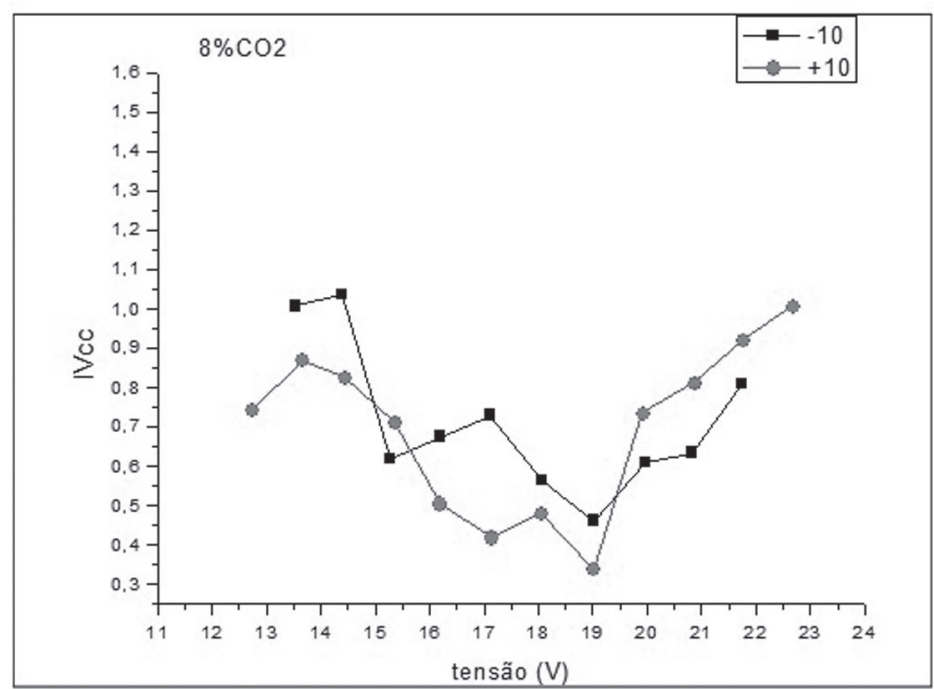

(a)

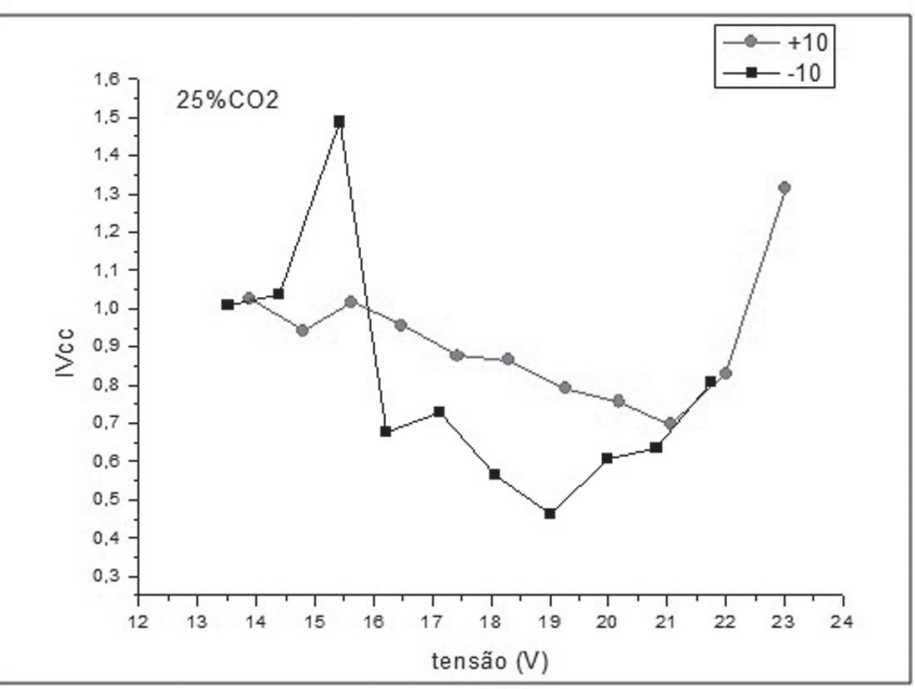

(b)

Figura 10 - Índice de regularidade em função da tensão de soldagem para as posições de regulagem do efeito indutivo da fonte, utilizando como gás de proteção a mistura em (a) $\mathrm{Ar}+8 \% \mathrm{CO}_{2}$ e em (b) $\mathrm{Ar}+25 \% \mathrm{CO}_{2}$

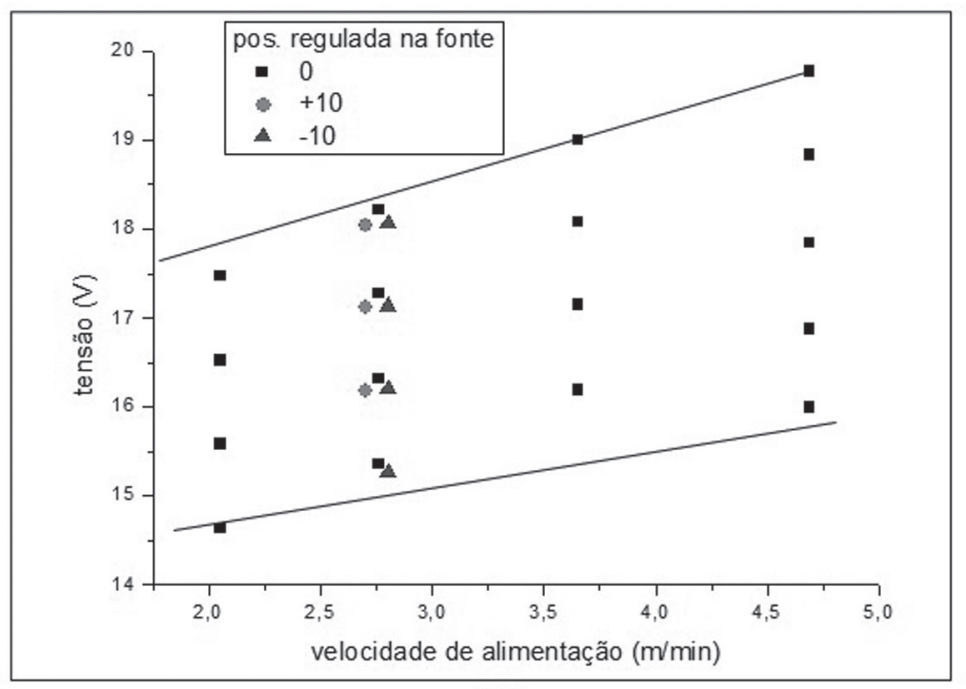

(a)

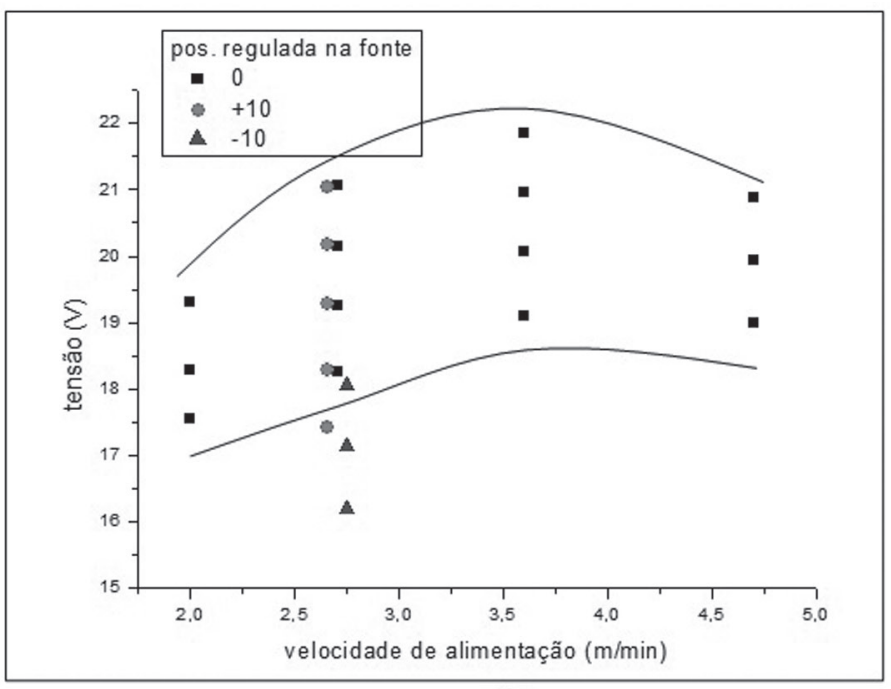

(b)

Figura 11 - Influência da taxa de crescimento e decrescimento da corrente na faixa de operação em curto-circuito estável para uma dada velocidade de alimentação, utilizando como gás de proteção em (a) $\mathrm{Ar}+8 \% \mathrm{CO}_{2}$ e em (b) $\mathrm{Ar}+25 \% \mathrm{CO}_{2}$

\section{Conclusões}

Para os parâmetros e condições utilizadas neste trabalho, pode-se concluir que:

- A correta seleção da tensão do arco, conseqüentemente comprimento de arco, é o que governa a parametrização para se obter soldagens com curto-circuito estável (transferência regular). Para cada velocidade de alimentação regulada haverá uma faixa de tensão adequada, a qual tem forte dependência para o gás de proteção e DBCP;

- A faixa operacional com transferência regular por curtocircuito apresenta valores de tensão mais altos para misturas à base de $\mathrm{Ar}$ mais ricas em $\mathrm{CO}_{2}$, mas o teor deste gás pouco influencia a corrente para uma dada velocidade de alimentação;

- Quanto menos $\mathrm{CO}_{2}$ na mistura, mais regular é a transferência metálica por curtos-circuitos;

- O aumento da DBCP, além de fazer o valor médio de corrente cair para uma mesma velocidade de alimentação, exige a diminuição da faixa de valores de tensão para que o processo opere na melhor estabilidade;

- Mudanças na taxa de crescimento e decrescimento da corrente, por meio da regulagem do controle indutivo do equipamento, não alteram significantemente os valores médios de corrente, tensão e freqüência de curto-circuito (pelo menos para o equipamento usado);

- As taxas de crescimento e decrescimento da corrente afetam a regularidade da transferência, mas o grau desta influência 
depende do gás de proteção utilizado e da tensão de soldagem;

- Por conseguinte, os resultados mostram que ao regular o processo (para um dado gás e DBCP), deve-se iniciar pela procura da faixa de tensão otimizada e, só então, procurar um ajuste fino pela regulagem do efeito indutivo.

\section{Agradecimentos}

Os autores deste trabalho gostariam de agradecer ao Laprosolda/UFU (Centro para Pesquisa e Desenvolvimento de Processos de Soldagem da Universidade Federal de Uberlândia) pelos consumíveis e infraestrutura laboratorial e ao $\mathrm{CNPq}$ pelas bolsas de estudo concedidas. Créditos são dados à Fapemig pelo financiamento da apresentação da versão inicial do trabalho no XXXV Consolda. Também agradecem à Air Products Brasil pelo fornecimento dos gases de proteção utilizados.

\section{Referências Bibliográficas}

[1] DUTRA, J. C.; BAIXO, C. E. I.; OLLÉ, L. F.; GOHR JÚNIOR, R. Instrumentação para Estudo da Transferência Metálica em Soldagem MIG/MAG por Curto-Circuito. In: XXI Encontro Nacional de Tecnologia da Soldagem, 1995, Caxias do Sul/RS. Anais do XXI Encontro Nacional de Tecnologia da Soldagem. São Paulo: Associação Brasileira de Soldagem, 1995. p. 867-888.

[2] HERMANS, M. J. M.; DEN OUDEN, G. Process Behavior and Stability in Short Circuit Gas Metal Arc Welding. Welding Journal. Welding Research Supplement, Volume 78, n 4, p. 137141, Apr 1999.

[3] NORRISH, J. Advanced Welding Process. 1. ed. London: IOP Publishing Ltd, 1992, 375p.

[4] BAIXO, C. E. I.; DUTRA, J. C. Influência da Taxa de Variação da Corrente na Regularidade em Soldagem MIG/MAG por Curto Circuito. In: XXI Encontro Nacional de Tecnologia da Soldagem, 1995, Caxias do Sul/RS. Anais do XXI Encontro Nacional de Tecnologia da Soldagem. São Paulo: Associação Brasileira de Soldagem, 1995. p. 903-920.

[5] FONSECA, A. F.; AVELAR, R. C.; MODENESI, P. J. Efeito de Variações nas Características de Arames na Soldagem GMAW por Curto-Circuito. In: XXII Encontro Nacional de Tecnologia da Soldagem, 1996, Blumenau/SC. Anais do XXII Encontro Nacional de Tecnologia da Soldagem. São Paulo: Associação Brasileira de Soldagem, 1996. p. 187-196.

[6] SILVA, A. V.; MARQUES, P. V.; MODENESI, P. J. Uma Avaliação da Transferência por Curto-Circuito GMAW. In: XX Encontro Nacional de Tecnologia da Soldagem, 1994, Contagem/MG. Anais do XX Encontro Nacional de Tecnologia da Soldagem. São Paulo: Associação Brasileira de Soldagem, 1994. p. 593-607.

[7] SUBAN, M.; TUSEK, J. Methods for the Determination of Arc Stability. Journal of Materials Processing Technology. p.430-437, 2003.

[8] ROCA, S. A.; FALS, H. C.; FERNÁNDEZ, J. B.; ADÁN, F. S. Application of U versus I Diagrams for Process Stability Evaluation in Gas Metal Arc Welding in Short Circuit Transfer
Mode. Soldagem \& Inspeção, Volume 10, n 2, p. 85-91, Abr/ Jun 2005.

[9] ROCA, S. A.; FALS, H. C.; FERNÁNDEZ, J. B.; MACÍAS, E. J.; ADÁN, F. S. New Stability Index for Short Circuit Transfer Mode in GMAW Process Using Acoustic Emission Signals. Science and Technology of Welding and Joining, Volume 12, $\mathrm{n}^{\circ}$ 5, p. 460-466, 2007.

[10] KANG, M. J.; RHEE, S. A Study on the Development of the Arc Stability Index Using Multiple Regression Analysis in the Short-Circuit Transfer Region of Gas Metal Arc Welding. Proceedings of the Institution of Mechanical Engineers, Part B: Journal of Engineering Manufacture, Volume 215, n 2, p. 195205, 2001.

[11] DUTRA, J. C. MIG/MAG - Transferência Metálica por Curto-Circuito - Fontes de Soldagem versus Gases do Arco. Soldagem e Inspeção. Volume 13, No 1, p.019-024, Jan/Mar 2008.

[12] SCOTTI, A., Mapping the Transfer Modes for Stainless Steel GMAW, J. of Science and Technology of Welding and Joining, Institute of Materials Publ, UK, Vol.5, No.4, 2000, pp. 227-234 (ISSN 1362-1718)

[13] SCOTTI, A.; PONOMAREV, V. Soldagem MIG/MAG: Melhor entendimento, melhor desempenho. 1. ed. São Paulo: Artliber Editora Ltda, 2008, 284p.

[14] FERREIRA FILHO, D.; FERRARESI, V. A. Influência do tipo de gás de proteção e da distância bico de contato-peça na transferência metálica do modo curto-circuito. In: XXXII CONSOLDA, 2006, Belo Horizonte. XXXII CONSOLDA, 2006.

[15] PONOMAREV, V.; AL-ERHAYEM, O.; APPS, R.L.; LINDBERG, B. Arc Welding Process Statistical Analysis Methodical Approaches, Analysis Conceptions, Experiences. Helsingor: The European Institute for the Joining of Materials, 1997, 158p. 